\title{
Risk of second primary cancers in cancer patients treated with cisplatin: a systematic review and meta-analysis of randomized studies
}

Fei Liang ${ }^{1}$, Sheng Zhang ${ }^{1,4^{*}}$, Hongxi Xue $^{2}$ and Qiang Chen ${ }^{3}$

\begin{abstract}
Background: Case reports, retrospective analyses, and observational studies have linked the use of cisplatin to increased risk of second cancers, especially life-threatening secondary leukemia. We therefore performed a systematic review and meta-analysis to evaluate the risk of second cancers associated with receipt of cisplatin-based chemotherapy in randomized controlled trials (RCTs).

Methods: We searched MEDLINE, Embase, the Cochrane Central Register of Controlled Trials, trial registers, conference proceedings, review articles, and reference lists of trial publications for all relevant RCTs comparing cisplatin- versus noncisplatin-containing chemotherapy with data on second cancers. We extracted data about study characteristics and second cancers, especially leukemia/ myelodysplasia. The primary and secondary outcomes were the odds ratios (ORs) for all second cancers and for secondary leukemia/ myelodysplasia, respectively.

Results: We identified 28 eligible trials with 7403 patients. Second cancers were reported in 143 patients, including 75 patients in the cisplatin arm and 68 in the non-cisplatin arm (raw event rates of 1.91 and 1.96\%, respectively). The pooled OR for risk of all second cancers associated with cisplatin-based chemotherapy was 0.95 ( $95 \%$ confidence interval $(C \mathrm{Cl})$ : 0.67-1.33, $P=0.76$ ). Secondary leukemia/ myelodysplasia was reported in 14 patients on cisplatin arms and in 6 patients on non-cisplatin arms of 11 eligible RCTs with 2629 patients (raw event rates of 1.09 and $0.45 \%$, respectively; pooled $\mathrm{OR}=2.34,95 \% \mathrm{Cl} 0.97-5.65, P=0.06$ ).

Conclusion: Cisplatin was not associated with a significantly increased risk of second cancers compared with noncisplatin-based chemotherapy. There is a non-significant trend to increased risk of leukemia/ myelodysplasia and the absolute risk was low. The concern about risk of second cancers should not influence decisions to use an efficacious regimen containing cisplatin.
\end{abstract}

Keywords: Second cancer, Cisplatin, Randomized controlled trials

\section{Background}

Second primary cancers in cancer survivors now constitute $18 \%$ of all cancer diagnoses in the US Surveillance, Epidemiology and End Results (SEER) cancer registries [1, 2]. In addition to this high morbidity, second cancers also lead to substantial mortality. For example, second primary

\footnotetext{
* Correspondence: wozhangsheng@hotmail.com

'Shanghai Cancer Center and Shanghai Medical College, Fudan University, Shanghai, China

${ }^{4}$ Medical Oncology, Shanghai Cancer Center, Fudan University, 270 Dongan Road, Shanghai 200032, China

Full list of author information is available at the end of the article
}

cancers have become the leading cause of mortality among patients with Hodgkin's lymphoma [1, 3, 4]. Thus, elucidation of factors leading to a second cancer and methods to avoid it may have substantial impact on both individual patient outcomes and public health. The increased risk of developing second cancers among cancer survivors is probably due to a combination of life-style, genetic factors, and treatment for the first cancer such as radiotherapy and certain chemotherapy regimens [3-5].

Since its introduction into clinical practice in 1970s, cisplatin, a chemotherapeutic agent binding to and causing 
crosslinking of DNA, has quickly become the cornerstone of modern chemotherapeutic treatment and been widely used worldwide because of its efficacies against various malignancies [6]. However, the persistence of platinum-DNA adducts in numerous human tissues long after treatment has completed has led to concerns that cisplatin-based chemotherapy might be associated with a greater risk of second cancers than other types of chemotherapy [6]. Indeed, it has been documented that cisplatin can be carcinogenic both in laboratory animals and humans [7-9]. Recently, using the population-based SEER cohort, Fung et al. found that cancer patients treated with cisplatin-based chemotherapy had a $40 \%$ increased risk of developing secondary solid cancers after initial diagnosis when they were compared with patients treated with surgery alone $[10,11]$. In a large case-control study of patients with testicular cancer, the estimated relative risk of leukemia was 3.2 (95\% confidence interval $[\mathrm{CI}]=1.5-8.4$ ) when cisplatin was given [12]. Another large case-control study of patients with ovarian cancer documented that the relative risks of leukemia was $3.3(95 \% \mathrm{CI}=1.1-9.4)$ for cisplatin treatment [13]. Moreover, strong dose-response relationships between cumulative cisplatin dose and secondary leukemia risk $(p<.001)$ were demonstrated in both studies $[12,13]$. These studies have seriously raised the concern about possible second cancer risk with the use of cisplatin. However, these studies were limited by their retrospective or observational design. In fact, there is no level-1 evidence showing an increased risk of second cancer associated with cisplatin-based chemotherapy in the context of the substantial number of patients that received cisplatin worldwide every year. Therefore, we performed an up-todate systematic review and meta-analysis to evaluate the effect of cisplatin on risk of second cancer in patients treated for their first cancer in RCTs with arms that compared chemotherapy regimens that did and did not include cisplatin.

\section{Methods}

\section{Selection criteria and search strategy}

The selection and systematic review of trials was performed in accordance with the Preferred Reporting Items for Systematic Review and Meta-Analyses (PRISMA) statement [14].

We searched Medline, Embase, and the Cochrane Central Register of Controlled Trials (CENTRAL) from inception to 24 March 2016. We combined both MeSH and free text words to identify relevant studies. The search strategy (Additional file 1) was developed based on an existing search strategy. ClinicalTrials.gov was also searched in June 2016 to ensure data from previously published trials were updated. We limited our search to "interventional" trials with available results. Conference
Proceedings from the American Society of Clinical Oncology and the European Society for Medical Oncology for the years 2010 to 2015 were also hand searched. Finally, reference of all eligible studies was also hand searched for other relevant citations.

Eligible studies were trials in which cancer patients were randomly assigned to treatment with cisplatin- versus non-cisplatin-containing chemotherapy. Studies that compared chemotherapy with radiotherapy, targeted therapy, surgery or placebo were excluded. In addition, eligible studies were required to report the incidence of second cancers in each treatment arm. Both the text and supplements of reports were screened to identify whether data on second cancers were available.

We used the Cochrane Collaboration's tool to assess the risk of bias of RCTs included in our study [15]. Random sequence generation, allocation concealment, blinding of participants, personnel, and assessors of outcome, incomplete outcome data and selective outcome reporting were judged to be of low, unclear, or high risk for each trial. We assessed potential publication bias by visual inspection of the symmetry of funnel plots and with the Begg and Egger tests.

\section{Data extraction}

For all eligible trials, we extracted the following data: trial phase, year of publication, underlying malignancy, length of follow-up, median age, adjuvant/metastatic setting, chemotherapy regimens used in each treatment arm, actual accumulative total cisplatin dose $\left(\mathrm{mg} / \mathrm{m}^{2}\right.$ ) (if not available, planned total dose was used), number of patients enrolled, the number and cancer types of all second cancers in each treatment arm. If insufficient data regarding second cancers were retrieved from publications, we sought it by contacting the corresponding authors.

For multiple reports of the same trial, we combined all data. Only data from the longest follow-up time was used when data was reported at multiple follow up periods.

Two authors (S.Z and F.L) independently screened trials for eligibility, assessed risk of bias and extracted required data from each included trials using standardized forms. Any discrepancy was identified and resolved successfully by consensus of all authors. Cronbach's alpha was 0.8 .

\section{Outcomes}

The primary outcome of this analysis is the odds ratios (OR) of second cancers associated with cisplatin- versus non-cisplatin-based chemotherapy. OR $>1$ means second cancers are more likely to occur in the cisplatin arm than in the non-cisplatin arm. The secondary outcome is the OR of second leukemia/myelodysplasia. 


\section{Statistical analysis}

Meta-analysis was performed with Review Manger 5.3

(Nordic Cochrane Centre, Cochrane Collaboration, 2014).

Many trials had few second cancers and the event rates were low, so the odds ratios and 95\% confidence intervals were calculated with the use of the Peto method $[15,16]$. Trials in which patients had no events in both cisplatin and non-cisplatin arms were excluded from meta-analyses. Heterogeneities were assessed using $\mathrm{X}^{2}$ test and the $\mathrm{I}^{2}$ statistic. A two-tailed $P$ value of less than 0.05 was considered as statistically significant.

To better understand the relationship between cisplatin and second cancers, we performed six pre-specified subgroup analyses stratifying patients by type of control in trials evaluating cisplatin versus another platinum agent or non-platinum chemotherapy (non-platinum control chemotherapy vs other platinum-based control chemotherapy) [17]; length of follow-up ( $\leq 60 \mathrm{vs}>60$ months); total cisplatin dose $\left(\leq 300 \mathrm{vs}>300 \mathrm{mg} / \mathrm{m}^{2}\right)$, mode of treatment (chemotherapy alone vs chemotherapy and radiotherapy), mode of comparison (confounded vs unconfounded), and setting (adjuvant vs metastasis).The designation of the cut-points of both length of follow and accumulative total cisplatin dose was based on previous studies $[12,13]$. Comparison of cisplatin arm and control arm were classified into three categories: cisplatin \pm other therapy regimen vs other cytotoxic drug \pm the same therapy regimen (eg. cisplatin vs carboplatin or doxorubicin and cisplatin vs doxorubicin and paclitaxel); cisplatin plus other chemotherapy regimens vs the same chemotherapy regimen without cisplatin(eg, epirubicin and cisplatin vs epirubicin); cisplatin plus other chemotherapy regimen vs different chemotherapy regimen (eg. cisplatin, doxorubicin and cyclophosphamide vs chlorambucil). The first two groups were considered to be un-confounded comparison [17-19].

Given concerns that Peto methods may not be ideal for evaluation of rare events with baseline event rate above $1 \%$, we also carried out sensitivity analyses using Mantel-Hanszel methods. We also conducted two extra sensitivity analyses by using alternative effect measure (odds ratio vs relative risk) and statistical models regarding heterogeneity (fixed vs random effects) to further assess the robustness of the results to the choice of this model for the meta-analysis.

\section{Results}

\section{Search results}

Our initial search yielded 33,429 records. After removing obvious duplicates and screening titles and abstracts, we retrieved 719 reports for full text screening. Twentyeight studies (27 from journals and one from conference abstract) were eligible for inclusion (Fig. 1) [20-47]. Two studies included multiple cisplatin arms, which were combined for this analysis. Of the 28 RCTs, 2 trials reported no incidence of any second cancers in both cisplatin and non-cisplatin arms, 15 trials reported the detailed information of cancer types of second cancers (10 trials reported incidence of secondary leukemia/myelodysplasia only), 11 trials did not provide detailed information of types of second cancers (Additional file 1: Table S1).

\section{Risk of bias}

None of the included trials was placebo controlled or double blinded, which would be difficult given the hydration and antiemetic therapy necessary with cisplatin-based chemotherapy. Most trials adequately generated their randomization sequence and concealed allocation, and the risk of incomplete and selective reporting of outcomes was assessed to be low. (Additional file 1: Table S2).

\section{Publication bias}

No evidence for publication bias was demonstrated based on the assessment of the funnel plot or formal analysis (Begg test, $P=0.96$; Egger test, $P=0.80$ ).

\section{Study, patient, and treatment characteristics}

A total of 7403 patients from 28 RCTs were included. The Characteristics of each trial are summarized in Table 1 . The trials were performed in patients with head and neck cancer (6 trials), ovarian cancer (6 trials), and other multiple types of cancer (16 trials). The control chemotherapy regimens consisted of other platinum-based therapy in eight trials (carboplatin, 7; oxaliplatin, 1) and non-platinum-based therapy in 20 trials. The leading underlying malignancies were head and neck cancers (6) and ovarian cancers (6). Accumulative total cisplatin dose was available for 27 trials, ranging from 64 to $580 \mathrm{mg} / \mathrm{m}^{2}$. Follow up time were reported or estimable in all trials, ranging from 17 to 156 months. Nine trials involved radiotherapy in both cisplatin and non-cisplatin arms. Mode of comparison was classified as un-confounded in 13 trials and confounded in 16 trials with one study included both confounded and un-confounded comparisons.

\section{Second cancers}

Second cancers were reported in 143 patients, including 75 patients in the cisplatin arm (raw event rate $1.91 \%$ ) and 68 in the non-cisplatin arm (raw event rate $1.96 \%)$. The incidence rate of second cancers varied among trials, ranging from 0 to $11.9 \%$. The highest incidence of second cancers was observed in a trial of 119 patients with head and neck cancers [39]. The estimated OR of second cancers for cisplatinversus non-cisplatin-based chemotherapy was 0.95 (95\% CI, 0.67-1.33, $P=0.76$ ) (Fig. 2). 


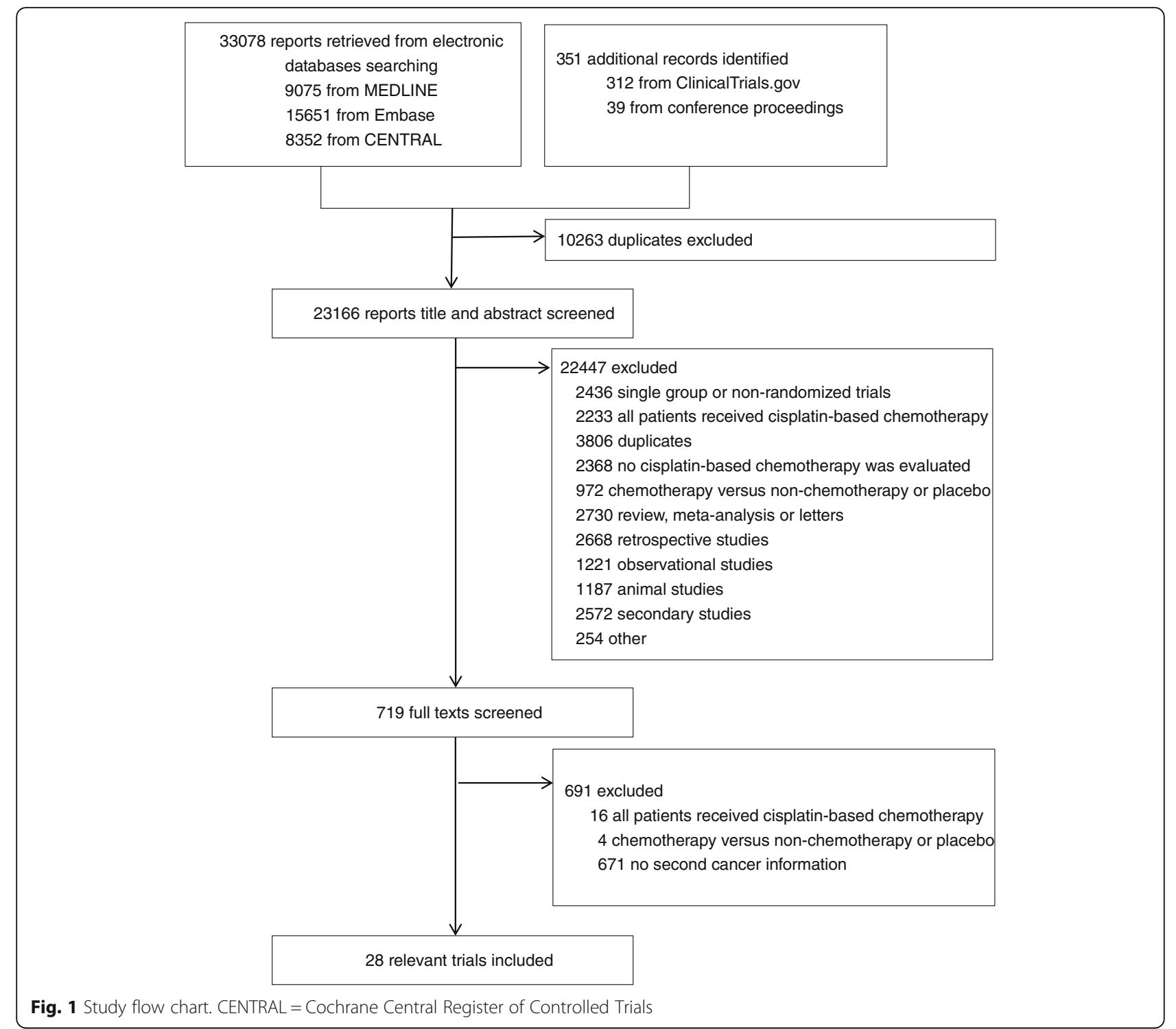

Secondary leukemia/myelodysplasia was reported in 11 eligible RCTs representing 2629 patients, whereas 17 studies did not report leukemia. It is unclear from the publications whether this reflects the absence of leukemia/myelodysplasia in these 17 studies or a failure to report this specific type of second cancers. Leukemia/ myelodysplasia was reported in 14 patients on cisplatin arm (raw event rate, 1.09\%,) and in 6 patients on noncisplatin arm (raw event rate, $0.45 \%$ ). The pooled OR was 2.34 (95\% CI, 0.97-5.65, $P=0.06$ ) (Fig. 3).

\section{Subgroup analyses}

To explore whether the possible increased risk of second malignancy was common to all platinum agents or unique to cisplatin, the control arm was further classified as platinum control or non-platinum control, according to whether other platinum agent such as oxaplatin or carboplatin was included. The subgroup analysis showed that cisplatin did not increase risk of second cancers compared with another platinum (OR 0.97, 95 CI 0.56-1.66) or non-platinum agents (OR 0.94, 95 CI 0.60-1.45) (Additional file 1: Figure S1). Neither high dose (OR 0.88, 95 CI 0.50-1.56) nor low dose (OR 0.94, 95 CI 0.61-1.46) was associated with increased risk of second cancers (Additional file 1: Figure S2). There was no significant relationship between the length of follow-up time and the pooled OR of second cancers $(0.99$ in trials with follow up time $\leq$ 60 months vs 0.89 in those $>60$ months; interaction $P$ $=0.77$ ) (Additional file 1: Figure S3). We also classified trials into chemotherapy alone or chemotherapy and radiotherapy. No significant interaction effect was identified between these subgroups $(0.90$ vs 0.99 ; interaction $P=0.78$ ) (Additional file 1: Figure S4). In some trials 


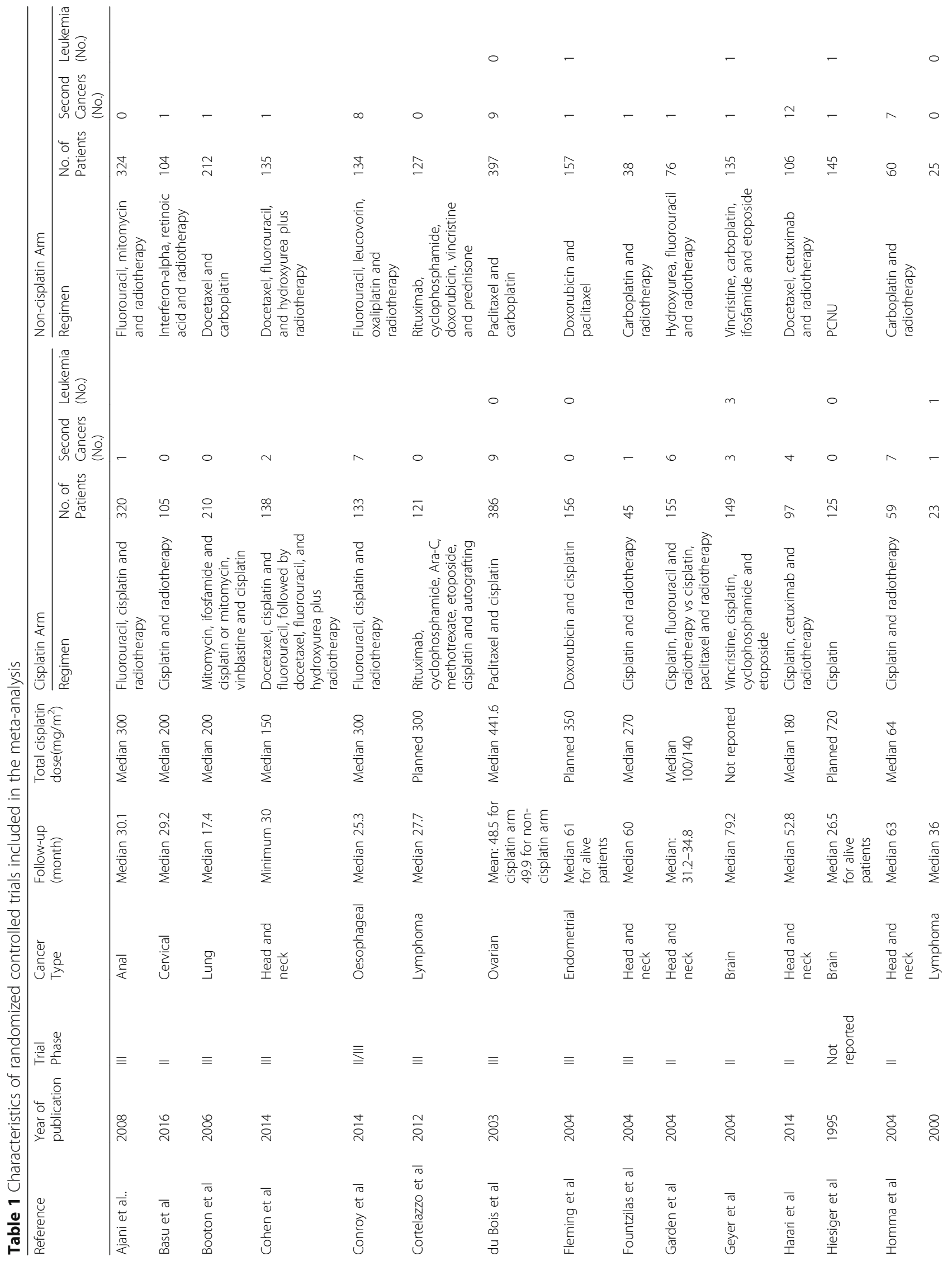




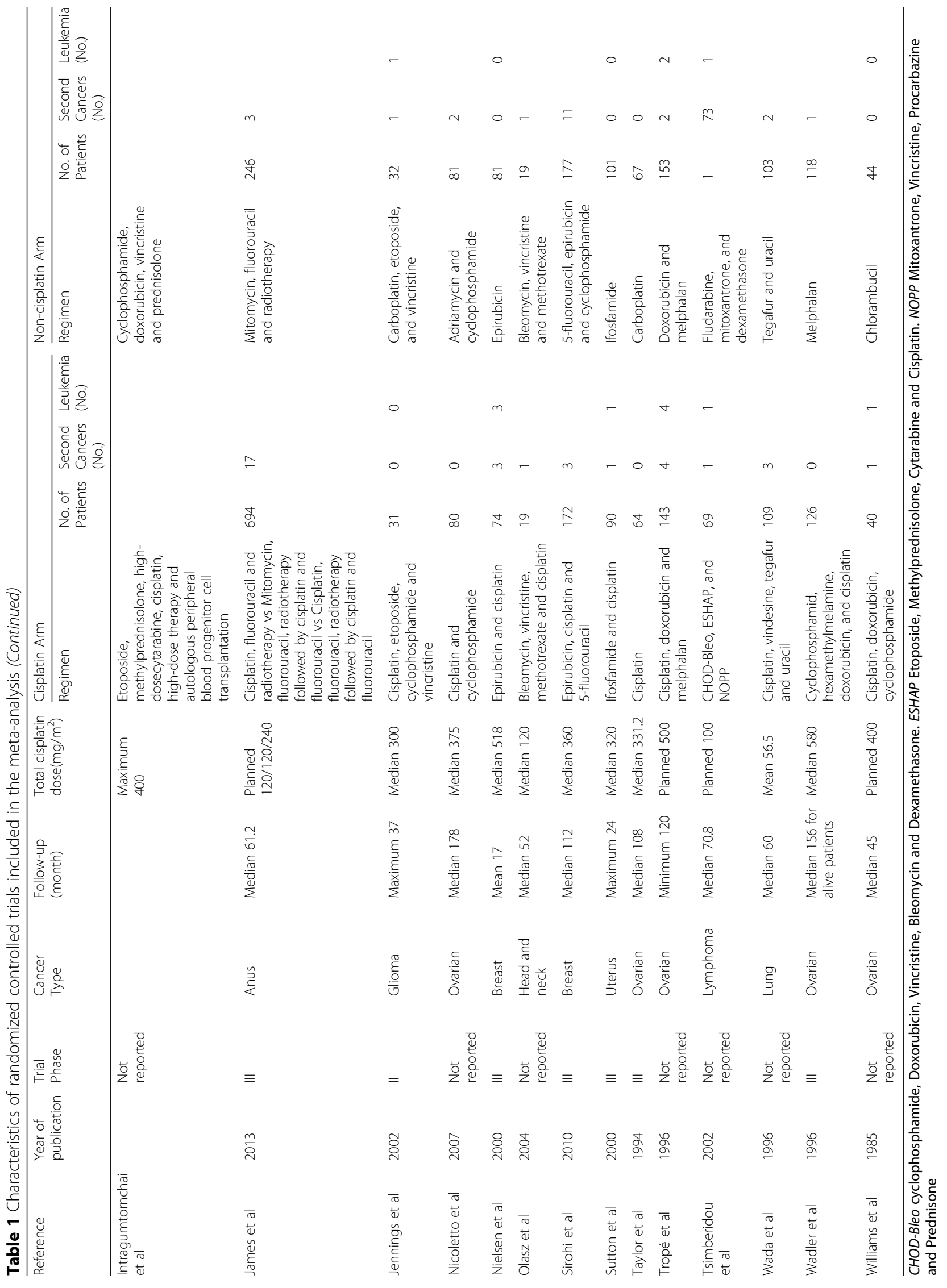




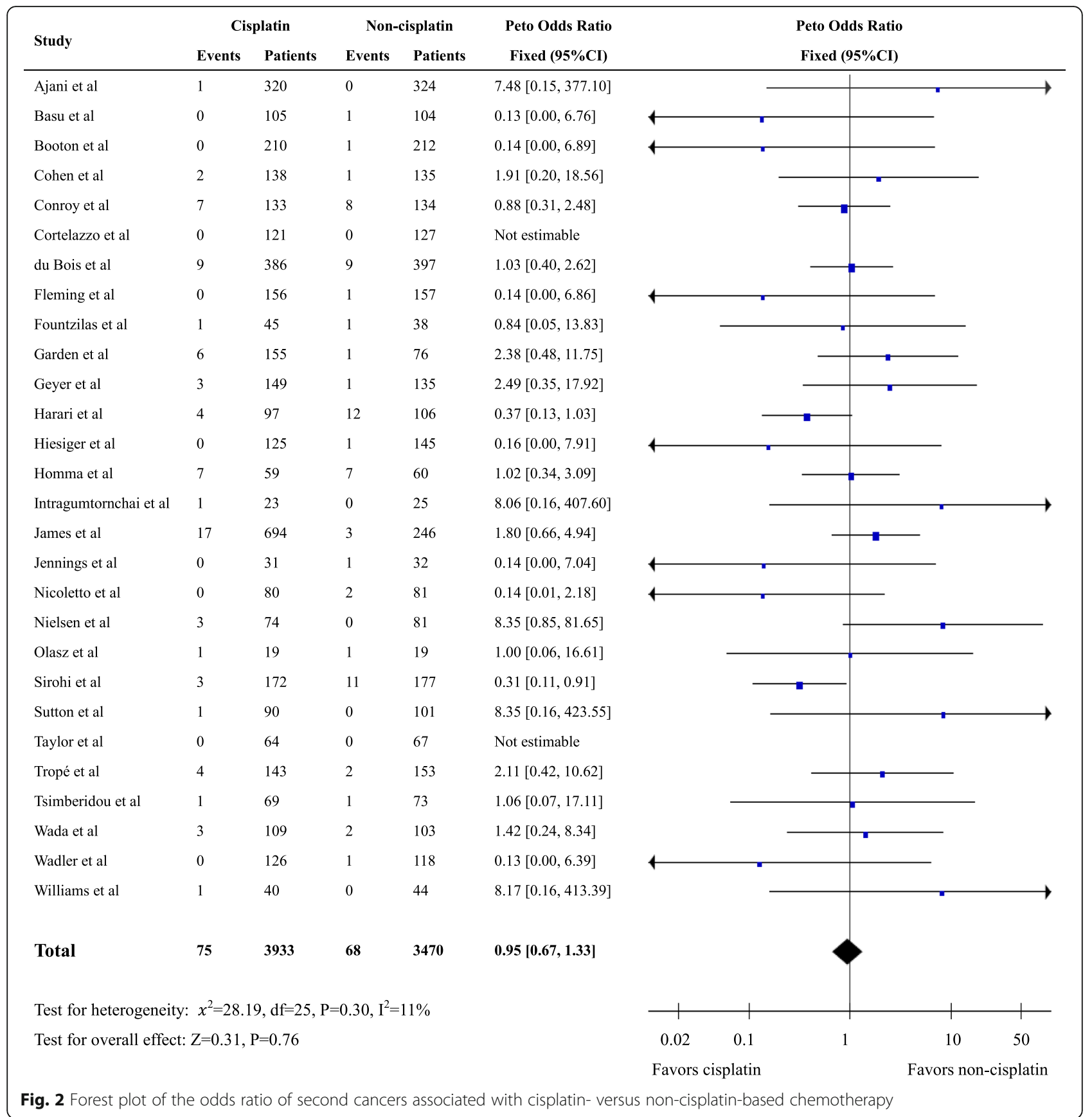

there were treatment regimen difference aside from cisplatin (eg, mitomycin, ifosfamide and cisplatin versus docetaxel and carboplatin). To address whether carcinogenicity of other regimen components would influence the results, we categorized trials into confounded or un-confounded according to the difference between treatment arms aside from cisplatin. There was no significant difference between the two subgroups (1.21 for confounded vs 0.88 for un-confounded; interaction $P=$ 0.40) (Additional file 1: Figure S5) (Table 2). There was no significant difference (interaction $P=0.50$ ) in the odds ratio of second cancers between cisplatin used in the adjuvant setting (Peto odds ratio $=0.90 ; 95 \% \mathrm{CI}$, $0.62-1.31$ ) and metastasis setting (Peto odds ratio $=1.18$; 95\% CI, 0.59-2.37) (Table 2).

\section{Sensitivity analysis}

The sensitivity analysis using alternative effect measure (odds ratio vs relative risk), pooling method (Peto vs Mantel-Hanszel), and statistical models regarding 


\begin{tabular}{|c|c|c|c|c|c|c|c|c|}
\hline \multirow{2}{*}{ Study } & \multicolumn{2}{|c|}{ Cisplatin } & \multicolumn{2}{|c|}{ Non-cisplatin } & \multirow{2}{*}{$\begin{array}{l}\text { Peto Odds Ratio } \\
\text { Fixed }(95 \% \mathrm{CI})\end{array}$} & \multirow{2}{*}{\multicolumn{3}{|c|}{$\begin{array}{l}\text { Peto Odds Ratio } \\
\text { Fixed }(95 \% \mathrm{CI})\end{array}$}} \\
\hline & Events & Patients & Events & Patients & & & & \\
\hline du Bois et al & 0 & 386 & 0 & 397 & Not estimable & & & \\
\hline Fleming et al & 0 & 156 & 1 & 157 & $0.14[0.00,6.86]$ & 4 & & \\
\hline Geyer et al & 3 & 149 & 1 & 135 & $2.49[0.35,17.92]$ & & & - \\
\hline Hiesiger et al & 0 & 125 & 1 & 145 & $0.16[0.00,7.91]$ & $\longleftarrow$ & & \\
\hline Intragumtornchai et al & 1 & 23 & 0 & 25 & $8.06[0.16,407.60]$ & & & \\
\hline Jennings et al & 0 & 31 & 1 & 32 & $0.14[0.00,7.04]$ & $\longleftarrow$ & & \\
\hline Nielsen et al & 3 & 74 & 0 & 81 & $8.35[0.85,81.65]$ & & & \\
\hline Sutton et al & 1 & 90 & 0 & 101 & $8.35[0.16,423.55]$ & & & \\
\hline Tropé et al & 4 & 143 & 2 & 153 & $2.11[0.42,10.62]$ & & & \\
\hline Tsimberidou et al & 1 & 69 & 0 & 73 & $7.83[0.16,395.22]$ & & & \\
\hline Williams et al & 1 & 40 & 0 & 44 & $8.17[0.16,413.39]$ & & & \\
\hline Total & 14 & 1286 & 6 & 1343 & $2.34[0.97,5.65]$ & & & \\
\hline \multicolumn{6}{|c|}{ Test for heterogeneity: $x^{2}=8.59, \mathrm{df}=9, \mathrm{P}=0.48, \mathrm{I}^{2}=0 \%$} & + & & + \\
\hline \multicolumn{6}{|c|}{ Test for overall effect: $\mathrm{Z}=1.89, \mathrm{P}=0.06$} & 0.02 & 1 & 10 \\
\hline & & & & & & Favors cisplatin & & Favors non-cisplatin \\
\hline
\end{tabular}

Table 2 Subgroup analysis of odds ratio (OR) of second cancers associated with cisplatin chemotherapy

\begin{tabular}{|c|c|c|c|c|c|c|c|c|c|}
\hline \multirow[t]{2}{*}{ Group } & \multirow{2}{*}{$\begin{array}{l}\text { No. of } \\
\text { trials }\end{array}$} & \multicolumn{2}{|l|}{ Cisplatin } & \multicolumn{2}{|l|}{ Non-cisplatin } & \multirow[t]{2}{*}{$I^{2}(\%)$} & \multirow[t]{2}{*}{ OR $(95 \% \mathrm{Cl})$} & \multicolumn{2}{|l|}{$P$} \\
\hline & & No. of events & No. of patients & No. of events & No. of patients & & & OR & Interaction \\
\hline Type of control & & & & & & & & & 0.93 \\
\hline Non-platinum & 20 & 48 & 2856 & 40 & 2395 & 29 & $0.94[0.60,1.45]$ & 0.77 & \\
\hline Other platinum & 8 & 27 & 1077 & 28 & 1075 & 0 & $0.97[0.56,1.66]$ & 0.90 & \\
\hline Total cisplatin dose $\left(\mathrm{mg} / \mathrm{m}^{2}\right)$ & & & & & & & & & 0.85 \\
\hline$\leq 300$ & 16 & 50 & 2461 & 41 & 1946 & 0 & $0.94[0.61,1.46]$ & 0.80 & \\
\hline$>300$ & 11 & 22 & 1323 & 26 & 1389 & 43 & $0.88[0.50,1.56]$ & 0.66 & \\
\hline Follow-up time(months) & & & & & & & & & 0.77 \\
\hline$\leq 60$ & 18 & 40 & 2221 & 39 & 2203 & 4 & $0.99[0.63,1.56]$ & 0.97 & \\
\hline$>60$ & 10 & 35 & 1712 & 29 & 1267 & 30 & $0.89[0.53,1.50]$ & 0.67 & \\
\hline Mode of treatment & & & & & & & & & 0.78 \\
\hline Chemotherapy alone & 19 & 30 & 2187 & 34 & 2247 & 19 & $0.90[0.55,1.48]$ & 0.68 & \\
\hline Chemotherapy and radiotherapy & 9 & 45 & 1746 & 34 & 1223 & 5 & $0.99[0.62,1.59]$ & 0.98 & \\
\hline Mode of comparison & & & & & & & & & 0.40 \\
\hline Un-confounded & 16 & 53 & 2602 & 51 & 2228 & 28 & $0.88[0.59,1.32]$ & 0.54 & \\
\hline Confounded & 13 & 22 & 1331 & 18 & 1318 & 0 & $1.21[0.65,2.28]$ & 0.54 & \\
\hline Treatment setting & & & & & & & & & 0.50 \\
\hline Adjuvant & 20 & 61 & 2747 & 56 & 2252 & 0 & $0.90[0.62,1.31]$ & 0.65 & \\
\hline Metastasis & 8 & 14 & 1186 & 12 & 1218 & 0 & $1.18[0.59,2.37]$ & 0.58 & \\
\hline
\end{tabular}


heterogeneity (fixed vs random model) did not show any important change in the pooled OR for both second cancers and leukemia/myelodysplasia (Additional file 1: Figures S6, S7, S8, S9, S10 and S11).

\section{Discussion}

Second primary cancer has become a substantial cause of morbidity and mortality in cancer survivors [1, 4]. Cisplatin-based chemotherapy can lead to cure or longterm remission in several types of cancer including testicular and ovarian cancer. Evaluation of long-term risk of second cancers due to cisplatin-based chemotherapy has become increasingly important in the context of the large number of patients receiving cisplatin worldwide each year [6]. We sought to comprehensively examine the relationship between cisplatin-based chemotherapy and risk of second cancer in patients with first cancer. Although a small number of patients with second cancers have been reported in RCTs of cisplatin-based chemotherapy, none of these trials were designed to have enough power to assess any potential risk of second cancer. Given the clinical significance of this topic, we pooled data from RCTs for further analysis. Indeed, our meta-analysis of 28 trials demonstrated that no increased risk of second cancer was associated with cisplatin-based chemotherapy versus those receiving non-cisplatin-based chemotherapy. This result is in contrast to previous reports from retrospective and observational studies [10-13], which were limited by selection bias and various known and unknown confounders. Randomized allocation of participants could avoid such biases. The result of meta-analysis of relevant RCTs represents the least biased evidence base in this regard. Other strengths of our study include the comprehensive search, careful selection of studies from published and non-published trials through various data sources.

Because only about half of the included studies provided detailed cancer types of second cancers, a further analysis of any types of second cancers cannot be performed. However, previous case-control studies have found possible association between cisplatin and second leukemia/myelodysplasia and documented a strong dose-response relationship [12, 13]. So we also explored the possible risk of second leukemia. We found a nonsignificant trend to increased risk of secondary leukemia $(p=0.06)$ in analysis of 11 studies with available data. It is noteworthy that the events are very low (16 in cisplatin arm versus 6 in non-cisplatin arm) and the confidence interval was wide. Due to the rarity of leukemia events, further studies to clarify this question may not be feasible. The length of follow-up duration has been well established to be associated with the incidence of second cancers $[4,48]$. The relatively short follow-up time of the RCTs included in our trials, with 18 of the
28 included trials reported a median follow-up time no more than 5 years, may contribute to the low incidence rate of second cancers. However, the determination of risk of second cancers associated with cisplatin- versus non-cisplatin-based chemotherapy, the primary endpoint of our study, should not be affected, because the design of most RCTs should provide for relatively balanced, if not equal, follow-up of patients in both study arms for the duration of observation. Thus, current study represents the largest study with available information. Although we cannot completely exclude the possibility that a statistically significant increase in relative risk was missed due to the few events in RCTs included and borderline significance of results of secondary leukemia, the rarity of events suggests that such a finding would be very unlikely to change current benefit-risk balance of cisplatin-based chemotherapy in clinical practice.

We also performed subgroup analyses to better understand the relationship between cisplatin and second cancer. Diverse chemotherapeutic reagents have been used. In some trials, there were treatment regimen differences aside from cisplatin. In this case, we cannot rule out the possible contribution to risk of second cancers by other regimen components. The subgroup analyses about unconfounded and confounded groups did not show any difference between these subgroups. Because radiotherapy was used in both treatment arms in 9 studies and radiotherapy is an established risk factor for increased second cancer in previous studies, we also performed subgroup analysis comparing the radiotherapy-involved studies versus radiotherapy-not-involved studies. Indeed, although higher incidence rate of second cancers was observed in the patients receiving radiotherapy and chemotherapy combination, no differences were found between these radiotherapy-involved or radiotherapy-not-involved subgroups. Other subgroup analyses regarding the total dose of cisplatin, follow-up time, control chemotherapy reagents consistently showed there were not differences among these subgroups.

Notably, the total cumulative cisplatin doses in included studies were much lower than that previously reported in observational studies in which significant association of secondary leukemia with cisplatin was demonstrated $[8,9,12,13,49]$, with majority of included trials reported total dose less than $300 \mathrm{mg} / \mathrm{m}^{2}$ and only one trial more than $600 \mathrm{mg} / \mathrm{m}^{2}$. In previous studies, total cisplatin dose at higher than $750 \mathrm{mg} / \mathrm{m}^{2}$ was associated with significantly increased risk of leukemia [12]. Modern chemotherapy regimens generally contain lower dose of cisplatin as reflected in the included RCTs, and this may contribute to the relatively low risk of second cancers or leukemia/myelodysplasia.

We should acknowledge other limitations in our study. The types of primary cancer in included trials are 
diverse, while previous conclusion about increased risk of second cancer associated with cisplation was drawn from studes in testicular cancer patients. Especially, the design of comparison of cisplatin versus non-cisplatin treatment arms may not be suited for investigation of germ cell tumors, where cisplatin has been the dominant and possibly the most significant chemotherapeutic. It is almost impossible to have RCTs comparing cispatin versus non-cisplatin treatments in the field of germ cell tumors because of ethical and medical reasons. In this case, the question of possible cisplatin-associated second cancers cannot be answered by our study and has to rely on population-based observational studies. Given the statistically nonsignificant results, we performed a posteriori power analyses [50]. We estimated the power of our meta-analysis for OR of 2.0 and 1.5 to be 99 and $75 \%$ (one-sided $\alpha$ of .05), respectively. Although a statistically significant increase in second cancers with cisplatin-based chemotherapy may have been missed, based on the observed incidence and relative risk, such an increase is very unlikely to change current benefit to risk balance for cisplatin. On the other hand, a sample size of 7646 will provide $80 \%$ power to rule out with $95 \%$ confidence an approximately $50 \%$ increase in the incidence of a secondary primary malignancy that occurs at a rate of $2 \%$ in the non-cisplatin group (i.e., $3 \%$ versus $2 \%)$. Because in this study, 7403 patients which is close to 7646 were included in the meta-analysis, it is reassuring that our study is not underpowered to identify small but important effects.

Another limitation is that multiple chemotherapy regimens given in the trials and various cancer types of primary cancer may limit the interpretation of our results, although we tried to perform subgroup analyses and sensitivitiy analyses. However, given that cisplatin is one of the most efficacious chemotherapeutic reagents and widely used in everyday clinical practice to treat various types of cancer, the data here are the best available from randomized trials. And the information provided here should be used for physicians and patients in the process of shared decision-making. Additionally, although an effect size was not able to be calculated for these trials, they do provide relevant data by showing that event rates for both the intervention and control groups are low and relatively equal. Friedrich [51] found that including zero total event trials in meta-analyses moves the pooled estimate of treatment effect closer to nil, but the magnitude of this increase is relatively small for RR and OR. Thus, inclusion of zero total event trials would enable the inclusion of all available randomized controlled trial data in our study, thereby providing the most generalizable estimate of treatment effect and would not significantly affect the pooled effects size.
Finally, the future reporting of long-term complications such as second cancers should be standardized. Detailed information regarding specific types of second cancers, corresponding number, location in treatment arms should be uniformly provided. Such information would be valuable when future secondary analyses of interest are performed.

\section{Conclusion}

We found no increased risk of second cancers associated with cisplatin compared with non-cisplatin-based chemotherapy and a non-significant trend to increased risk of secondary leukemia. But the absolute risk is very low. The concern of possible risk of second cancers should not influence a decision to use an efficacious regimen containing cisplatin. This finding should be important for patient counseling and shared-decision making.

\section{Additional file}

Additional file 1: Strategy of trials searching. (DOCX $806 \mathrm{~kb}$ )

\section{Abbreviations}

CENTRAL: Cochrane Central Register of Controlled Trials; Cl: Confidence interval; OR: Odds ratio; PRISMA: Preferred Reporting Items for Systematic Review and Meta-Analyses statement; RCT: Randomized controlled trials; SEER: Surveillance Epidemiology and End Results

\section{Acknowledgments}

We thank Dr. Ian Tannock, Princess Margaret Cancer Centre and University of Toronto, for his assistance in reading and editing the manuscript.

\section{Funding}

Not applicable.

\section{Availability of data and materials}

Data extracted from published manuscript is available from the senior author atwozhangsheng@hotmail.com.

\section{Authors' contributions}

Dr. SZ conceived the study. All four authors analyzed and interpreted the data. All authors drafted and revised the nanuscript, and all approved this version. SZ is the guarantor. The lead author (SZ) affirms that the manuscript is an honest, accurate, and transparent account of the study being reported; that no important aspects of the study have been omitted; and that any discrepancies from the study as planned (and, if relevant, registered) have been explained. All authors read and approved the final manuscript.

Ethics approval and consent to participate

Ethics approval was not required for this study because it was based on publicly available data and involved no individual patient data collection or analysis

Consent for publication

All authors have consented for this publication.

\section{Competing interests}

For Sheng Zhang: None, For Fei Liang: None, For Hongxi Xue: None, For Qiang Chen: None. We declare that Dr. Sheng Zhang and Fei Liang had full access to all of the data in the study and take responsibility for the integrity of the data and the accuracy of the data analysis. 


\section{Publisher's Note}

Springer Nature remains neutral with regard to jurisdictional claims in published maps and institutional affiliations.

\begin{abstract}
Author details
'Shanghai Cancer Center and Shanghai Medical College, Fudan University, Shanghai, China. ${ }^{2}$ Rizhao City Hospital of Traditional Chinese Medicine, 35 Wanghai Road, Rizhao, China. ${ }^{3}$ Department of clinical biochemistry, School of public health Taishan medical university, Taishan, China. ${ }^{4}$ Medical Oncology, Shanghai Cancer Center, Fudan University, 270 Dongan Road, Shanghai 200032, China.
\end{abstract}

Received: 31 December 2016 Accepted: 8 December 2017 Published online: 19 December 2017

\section{References}

1. Miller KD, Siegel RL, Lin CC, Mariotto AB, Kramer JL, Rowland JH, Stein KD, Alteri $\mathrm{R}$, Jemal A. Cancer treatment and survivorship statistics, 2016. CA Cancer J Clin. 2016;66(4):271-89.

2. Berrington de Gonzalez A, Curtis RE, Kry SF, Gilbert E, Lamart S, Berg CD, Stovall M, Ron E. Proportion of second cancers attributable to radiotherapy treatment in adults: a cohort study in the US SEER cancer registries. Lancet Oncol. 2011;12(4):353-60.

3. Morton LM, Swerdlow AJ, Schaapveld M, Ramadan S, Hodgson DC, Radford $J$, van Leeuwen FE. Current knowledge and future research directions in treatment-related second primary malignancies. EJC suppl. 2014;12(1):5-17.

4. Wood ME, Vogel V, Ng A, Foxhall L, Goodwin P, Travis LB. Second malignant neoplasms: assessment and strategies for risk reduction. J clin oncol. 2012; 30(30):3734-45.

5. Travis LB. Therapy-associated solid tumors. Acta oncol. 2002;41(4):323-33.

6. Muggia FM, Bonetti A, Hoeschele JD, Rozencweig M, Howell SB. Platinum antitumor complexes: 50 years since Barnett Rosenberg's discovery. J clin oncol. 2015:33(35):4219-26.

7. Greene $\mathrm{MH}$. Is cisplatin a human carcinogen? J Natl Cancer Inst. 1992;84(5):306-12.

8. Pedersen-Bjergaard J, Daugaard G, Hansen SW, Philip P, Larsen SO, Rorth M. Increased risk of myelodysplasia and leukaemia after etoposide, cisplatin and bleomycin for germ-cell tumours. Lancet. 1991;338(8763):359-63.

9. Adra N, Sayar H, Einhorn LH. Chemotherapy-related chronic Myelogenous leukemia: a case series of patients with germ cell tumor. JAMA oncol. 2016:2(3):391-2

10. Fung C, Fossa SD, Milano MT, Oldenburg J, Travis LB. Solid tumors after chemotherapy or surgery for testicular nonseminoma: a population-based study. J clin oncol. 2013;31(30):3807-14.

11. Gandaglia G, Karakiewicz PI, Trinh QD, Sun M. Cisplatin-based chemotherapy and the risk of solid tumors in patients with testicular nonseminoma: still a matter of debate. J clin oncol. 2014;32(11):1167.

12. Travis LB, Andersson M, Gospodarowicz M, van Leeuwen FE, Bergfeldt K, Lynch CF, Curtis RE, Kohler BA, Wiklund T, Storm H, et al. Treatment-associated leukemia following testicular cancer. J Natl Cancer Inst. 2000;92(14):1165-71.

13. Travis LB, Holowaty EJ, Bergfeldt K, Lynch CF, Kohler BA, Wiklund T, Curtis RE, Hall P, Andersson M, Pukkala E, et al. Risk of leukemia after platinumbased chemotherapy for ovarian cancer. N Engl J Med. 1999;340(5):351-7.

14. Moher D, Liberati A, Tetzlaff J, Altman DG. Preferred reporting items for systematic reviews and meta-analyses: the PRISMA statement. BMJ. 2009; 339:b2535.

15. Higgins JPTADSJ. Assessing risk of bias in included studies. In: Cochrane handbook for systematic reviews of interventions. Version $510 \mathrm{ed}$. Cochrane Collaboration; 2011.

16. Bradburn MJ, Deeks JJ, Berlin JA, Russell Localio A. Much ado about nothing: a comparison of the performance of meta-analytical methods with rare events. Stat Med. 2007;26(1):53-77.

17. Seng S, Liu Z, Chiu SK, Proverbs-Singh T, Sonpavde G, Choueiri TK, Tsao CK, Yu M, Hahn NM, Oh WK, et al. Risk of venous thromboembolism in patients with cancer treated with Cisplatin: a systematic review and meta-analysis. J clin oncol. 2012;30(35):4416-26.

18. Li L, Li S, Deng K, Liu J, Vandvik PO, Zhao P, Zhang L, Shen J, Bala MM, Sohani $Z N$, et al. Dipeptidyl peptidase-4 inhibitors and risk of heart failure in type 2 diabetes: systematic review and meta-analysis of randomised and observational studies. BMJ. 2016:352:1610.
19. Li L, Shen J, Bala MM, Busse JW, Ebrahim S, Vandvik PO, Rios LP, Malaga G, Wong E, Sohani Z, et al. Incretin treatment and risk of pancreatitis in patients with type 2 diabetes mellitus: systematic review and meta-analysis of randomised and non-randomised studies. BMJ. 2014;348:92366.

20. Ajani JA, Winter KA, Gunderson LL, Pedersen J, Benson AB 3rd, Thomas CR Jr, Mayer RJ, Haddock MG, Rich TA, Willett C. Fluorouracil, mitomycin, and radiotherapy vs fluorouracil, cisplatin, and radiotherapy for carcinoma of the anal canal: a randomized controlled trial. JAMA. 2008;299(16):1914-21.

21. Basu P, Jenson AB, Majhi T, Choudhury P, Mandal R, Banerjee D, Biswas J, Pan J, Rai SN, Ghim SJ, et al. Phase 2 randomized controlled trial of radiation therapy plus concurrent interferon-alpha and retinoic acid versus Cisplatin for stage III cervical carcinoma. Int J Radiat Oncol Biol Phys. 2016;94(1):102-10.

22. Booton R, Lorigan $\mathrm{P}$, Anderson H, Baka S, Ashcroft L, Nicolson M, O'Brien M, Dunlop D, O'Byrne K, Laurence V, et al. A phase III trial of docetaxel/ carboplatin versus mitomycin C/ifosfamide/cisplatin (MIC) or mitomycin C/ vinblastine/cisplatin (MVP) in patients with advanced non-small-cell lung cancer: a randomised multicentre trial of the British thoracic oncology group (BTOG1). Ann Oncol. 2006;17(7):1111-9.

23. Cohen EE, Karrison TG, Kocherginsky M, Mueller J, Egan R, Huang CH, Brockstein BE, Agulnik MB, Mittal BB, Yunus F, et al. Phase III randomized trial of induction chemotherapy in patients with N2 or N3 locally advanced head and neck cancer. J clin oncol. 2014;32(25):2735-43.

24. Conroy T, Galais MP, Raoul JL, Bouche O, Gourgou-Bourgade S, Douillard JY, Etienne PL, Boige V, Martel-Lafay I, Michel P, et al. Definitive chemoradiotherapy with FOLFOX versus fluorouracil and cisplatin in patients with oesophageal cancer (PRODIGE5/ACCORD17): final results of a randomised, phase 2/3 trial. Lancet Oncol. 2014;15(3):305-14

25. Cortelazzo S, Tarella C, Gianni AM, Barbui T, Ladetto M, Barbui AM, Rossi A, Corradini P, Di Nicola M, Patti C, et al. Chemoimmunotherapy with R-CHOP or high dose sequential therapy with autologous stem cell transplantation (R-HDS) for high risk diffuse large B-cell lymphomas patients: results of the randomized R-HDS0305 trial by gruppo italiano terapie innovative nei linfomi (GITIL). Blood Conference: 54th Annual Meeting of the American Society of Hematology, ASH. 2012;120(21).

26. du Bois A, Luck HJ, Meier W, Adams HP, Mobus V, Costa S, Bauknecht T, Richter B, Warm M, Schroder W, et al. A randomized clinical trial of cisplatin/ paclitaxel versus carboplatin/paclitaxel as first-line treatment of ovarian cancer. J Natl Cancer Inst. 2003;95(17):1320-9.

27. Fleming GF, Filiaci VL, Bentley RC, Herzog T, Sorosky J, Vaccarello L, Gallion $H$. Phase III randomized trial of doxorubicin + cisplatin versus doxorubicin + 24-h paclitaxel + filgrastim in endometrial carcinoma: a gynecologic oncology group study. Ann Oncol. 2004;15(8):1173-8.

28. Fountzilas G, Ciuleanu E, Dafni U, Plataniotis G, Kalogera-Fountzila A, Samantas E, Athanassiou E, Tzitzikas J, Ciuleanu T, Nikolaou A, et al. Concomitant radiochemotherapy vs radiotherapy alone in patients with head and neck cancer: a Hellenic cooperative oncology group phase III study. Med Oncol. 2004;21(2):95-107.

29. Garden AS, Harris J, Vokes EE, Forastiere AA, Ridge JA, Jones C, Horwitz EM, Glisson BS, Nabell L, Cooper JS, et al. Preliminary results of radiation therapy oncology group 97-03: a randomized phase ii trial of concurrent radiation and chemotherapy for advanced squamous cell carcinomas of the head and neck. J clin oncol. 2004;22(14):2856-64.

30. Geyer JR, Sposto R, Jennings M, Boyett JM, Axtell RA, Breiger D, Broxson E, Donahue B, Finlay JL, Goldwein JW, et al. Multiagent chemotherapy and deferred radiotherapy in infants with malignant brain tumors: a report from the Children's cancer group. J clin oncol. 2005;23(30):7621-31.

31. Harari PM, Harris J, Kies MS, Myers JN, Jordan RC, Gillison ML, Foote RL, Machtay M, Rotman M, Khuntia D, et al. Postoperative chemoradiotherapy and cetuximab for high-risk squamous cell carcinoma of the head and neck: radiation therapy oncology group RTOG-0234. J clin oncol. 2014:32(23):2486-95.

32. Hieseger EM, Green SB, Shapiro WR, Burger PC, Selker RG, Mahaley MS Jr, Ransohoff IJ, VanGilder JC, Mealey J Jr, Robertson JT, et al. Results of a randomized trial comparing intra-arterial cisplatin and intravenous PCNU for the treatment of primary brain tumors in adults: brain tumor cooperative group trial 8420A. J Neuro-Oncol. 1995;25(2):143-54.

33. Homma A, Shirato H, Furuta Y, Nishioka T, Oridate N, Tsuchiya K, Nagahashi T, Aoyama H, Inuyama Y, Fukuda S. Randomized phase II trial of concomitant chemoradiotherapy using weekly carboplatin or daily low-dose cisplatin for squamous cell carcinoma of the head and neck. Cancer J. 2004;10(5):326-32.

34. Intragumtornchai T, Prayoonwiwat W, Numbenjapon T, Assawametha N, O'Charoen R, Swasdikul D. CHOP versus CHOP plus ESHAP and high-dose 
therapy with autologous peripheral blood progenitor cell transplantation for high-intermediate-risk and high-risk aggressive non-Hodgkin's lymphoma. Clin Lymphoma. 2000;1(3):219-25.

35. James RD, Glynne-Jones R, Meadows HM, Cunningham D, Myint AS, Saunders MP, Maughan T, McDonald A, Essapen S, Leslie M, et al. Mitomycin or cisplatin chemoradiation with or without maintenance chemotherapy for treatment of squamous-cell carcinoma of the anus (ACT II): a randomised, phase 3, openlabel, 2 × 2 factorial trial. Lancet Oncol. 2013;14(6):516-24.

36. Jennings MT, Sposto R, Boyett JM, Vezina LG, Holmes E, Berger MS, Bruggers CS, Bruner JM, Chan KW, Dusenbery KE, et al. Preradiation chemotherapy in primary high-risk brainstem tumors: phase II study CCG-9941 of the Children's cancer group. J clin oncol. 2002;20(16):3431-7.

37. Nicoletto MO, Tumolo S, Sorio R, Cima G, Endrizzi L, Nascimben O, Vinante O, Artioli G, Donach M, Cartei G. Long-term survival in a randomized study of nonplatinum therapy versus platinum in advanced epithelial ovarian cancer. Int J Gynecol Cancer. 2007;17(5):986-92.

38. Nielsen D, Dombernowsky P, Larsen SK, Hansen OP, Skovsgaard T. Epirubicin or epirubicin and cisplatin as first-line therapy in advanced breast cancer. A phase III study. Cancer Chemother Pharmacol. 2000;46(6):459-66.

39. Olasz L, Nemeth A, Nyarady Z, Tornoczky T, Kiralyfalvi L. Results and failures with or without cisplatin containing induction chemotherapy in the treatment of squamous cell carcinoma of the head and neck. Cancer Detect Prev. 2004;28(1):65-71.

40. Sirohi B, A'Hern R, Coombes G, Bliss JM, Hickish T, Perren T, Crawford M, O'Brien M, Iveson T, Ebbs $\mathrm{S}$, et al. A randomised comparative trial of infusional ECisF versus conventional FEC as adjuvant chemotherapy in early breast cancer: the TRAFIC trial. Ann Oncol. 2010;21(8):1623-9.

41. Sutton G, Brunetto VL, Kilgore L, Soper JT, McGehee R, Olt G, Lentz SS, Sorosky J, Hsiu JG. A phase III trial of ifosfamide with or without cisplatin in carcinosarcoma of the uterus: a gynecologic oncology group study. Gynecol Oncol. 2000;79(2):147-53.

42. Taylor AE, Wiltshaw E, Gore ME, Fryatt I, Fisher C. Long-term follow-up of the first randomized study of cisplatin versus carboplatin for advanced epithelial ovarian cancer. J clin oncol. 1994;12(10):2066-70.

43. Trope C, Andersson H, Bjorkholm E, Frankendal B, Himmelman A, Hogberg T, Horvath G, Petterson B, Persson H, Ryberg M, et al. Doxorubicin-melphalan with and without cisplatin in advanced ovarian cancer-ten-year survival results from a prospective randomized study by the Swedish cooperative ovarian cancer study group. Acta Oncol. 1996;35(Suppl 8):109-18.

44. Tsimberidou AM, McLaughlin P, Younes A, Rodriguez MA, Hagemeister FB, Sarris A, Romaguera J, Hess M, Smith TL, Yang Y, et al. Fludarabine, mitoxantrone, dexamethasone (FND) compared with an alternating triple therapy (ATT) regimen in patients with stage IV indolent lymphoma. Blood. 2002;100(13):4351-7.

45. Wada H, Hitomi S, Teramatsu T. Adjuvant chemotherapy after complete resection in non-small-cell lung cancer. West Japan study Group for Lung Cancer Surgery. J clin oncol. 1996;14(4):1048-54.

46. Wadler S, Yeap B, Vogl S, Carbone P. Randomized trial of initial therapy with melphalan versus cisplatin-based combination chemotherapy in patients with advanced ovarian carcinoma: initial and long term results-eastern cooperative oncology group study E2878. Cancer. 1996;77(4):733-42.

47. Williams CJ, Mead GM, Macbeth FR, Thompson J, Whitehouse JM, MacDonald H, Harvey VJ, Slevin ML, Lister TA, Shepherd JH, et al. Cisplatin combination chemotherapy versus chlorambucil in advanced ovarian carcinoma: mature results of a randomized trial. J clin oncol. 1985;3(11):1455-62.

48. Wiltink LM, Nout RA, Fiocco M, Meershoek-Klein Kranenbarg E, JurgenliemkSchulz IM, Jobsen JJ, Nagtegaal ID, Rutten HJ, van de Velde CJ, Creutzberg $\mathrm{CL}$, et al. No increased risk of second cancer after radiotherapy in patients treated for rectal or endometrial cancer in the randomized TME, PORTEC-1, and PORTEC-2 trials. J clin oncol. 2015:33(15):1640-6.

49. Morton LM, Dores GM, Tucker MA, Kim CJ, Onel K, Gilbert ES, Fraumeni JF $\mathrm{Jr}$, Curtis RE. Evolving risk of therapy-related acute myeloid leukemia following cancer chemotherapy among adults in the United States, 19752008. Blood. 2013;121(15):2996-3004.

50. Hedges LV, Pigott TD. The power of statistical tests in meta-analysis. Psychol Methods. 2001;6(3):203-17.

51. Friedrich JO, Adhikari NK, Beyene J. Inclusion of zero total event trials in meta-analyses maintains analytic consistency and incorporates all available data. BMC Med Res Methodol. 2007;7:5.

\section{Submit your next manuscript to BioMed Central and we will help you at every step:}

- We accept pre-submission inquiries

- Our selector tool helps you to find the most relevant journal

- We provide round the clock customer support

- Convenient online submission

- Thorough peer review

- Inclusion in PubMed and all major indexing services

- Maximum visibility for your research

Submit your manuscript at www.biomedcentral.com/submit
( ) BioMed Central 